\title{
Is Demand Side Response a woman's work? Domestic labour and electricity shifting in low income homes in the United Kingdom
}

\section{Charlotte Johnson}

UCL Energy Institute, UCL, Central House, 14 Upper Woburn House, London WC1H ONN c.johnson@ucl.ac.uk

Orcid ID 0000-0002-7340-1601

Accepted for publication in Energy Research \& Social Science, Vol.68 (Nov).

\section{Abstract:}

This paper discusses a utility-led research project which piloted smart meters and DSR products (a time of use tariff and a critical peak rebate scheme) with 500 low income households in London. As households set about the task of adjusting their electricity use in response to shifting prompts, they revealed the importance of managing domestic labour to generate value from DSR products and the role of women in carrying this out. The experience is at odds with the smart future more typically imagined in which chore-doing is handed over to feminized Al assistants who orchestrate loT appliances to create comfort and capture value. Strengers has cautioned against constructing a smart future to serve 'Resource Man'. Drawing on trial participants' experiences, the paper develops the concept of 'Flexibility Woman' in order to bring the realities of domestic labour more sharply into focus. The paper argues that chore-doing needs to become a narrative in the smart future to understand the burdens and opportunities for 'Flexibility Woman' to create value from her labour. It suggests that women unable to afford a surrogate Al wife may find themselves becoming 'Flexibility Woman' or else excluded from accessing the cheaper, greener electricity of the future. It also suggests that ignoring gender risks undermining the impacts that policy makers and network operators hope to achieve through DSR.

The paper makes a unique contribution to our understanding of how DSR relates to gender roles and what the implications are for the effectiveness and inclusivity of flexibility products.

\section{Key words}

Flexibility; Demand Side Response; gender; material culture; infrastructure; distributional impacts 


\section{Introduction}

Demand side response (DSR) refers to a suite of initiatives that encourage and enable energy consumers to adjust their consumption in response to network signals [1]. In being able to adjust the demand for energy, such initiatives offer energy systems a number of benefits including avoiding the costly expansions of infrastructure network capacity, increasing the use of lower cost energy sources such as solar and wind, reducing the use of polluting fossil fuel generators, and reducing the risk of overloading networks and creating power cuts. DSR is therefore currently being pursued by governments and industry as a component of future electricity systems around the world [2]. National smart metering programmes support the introduction of DSR. In the UK, the smart meters currently being rolled out provide half hourly data on electricity consumption to suppliers and almost real time data to customers via an in-home display, in both kWh and monetary values. DSR products are already being offered by some energy suppliers in the form of time of use tariffs or automatic/ direct load control. The UK Government is interested in improving the electricity system, but also in ensuring that the benefits of this infrastructural upgrade are spread throughout the population [3]. The project 'Energywise' discussed in this paper falls within this remit; it was a government-regulated field trial of smart meters and DSR products that investigated the potential impacts on low income and vulnerable households.

Energywise trialled two non-punitive flexibility products; a time of use (ToU) tariff for smart credit meter users and a critical peak rebate (CPR) scheme for smart prepayment meter users. This was the first UK trial of non-punitive offers and the first to include smart prepayment meter households. In addition, over $60 \%$ of the people consenting to the flexibility trial were women, previous trials have seen a majority of male participants. The assumed gender neutrality of energy policy in the global north has been identified as a critical research area by Ryan in the agenda setting first issue of this journal [4]. Ignoring gender has been shown to undermine the transition to a sustainable energy system [5] and risks reproducing existing inequalities [6]. This paper therefore makes a unique contribution to our understanding of how demand side response relates to gender roles and what the implications are for the effectiveness and inclusivity of flexibility products. The paper presents qualitative research conducted with participants on how they understood the 
flexibility products they were being offered, why they consented to try them out and how those that consented made them work. Participants' motivations included saving money, enjoying the challenge of being disciplined and contributing to a better or greener electricity system. Their strategies included shifting chores, arbitraging between gas and electricity, critically reflecting on their household's electricity consumption, and mobilising family members. These efforts and experiences are analysed using a material culture lens in order to; 1) identify participants' understanding of their own agency in producing energy system flexibility, 2) develop ways to highlight gender in the design of flexibility products and 3) reflect on distributional impacts in the developing DSR markets around the world.

The paper starts with an overview of literature which has engaged with the relationship between chore-doing and energy system transition, before summarizing existing evidence about women's roles in DSR programmes and how a material culture framework provides a critical lens to engage with these insights. Section two outlines the Energywise trial which took place in social housing in east London and the qualitative methods used. Section three discusses households' experiences of these DSR products and analyses accounts from the households that tried to shift their consumption, and those that did not. Section 4 introduces the idea of 'Flexibility Woman' a subject position created within the smart electricity system and explores the political implications this raises, from enabling wider participation in the production of smart electricity systems to creating inequalities.

\section{Chore-doing and energy system transition}

Chore-doing is intimately related to energy system transition. The supply of utilities to the home created new forms of domestic labour and responsibility for carrying this labour out fell on the woman of the house, as Schwartz Cowan's [7] seminal monograph 'More Work for Mother' shows. Chore-doing became a way to express norms of comfort, convenience and cleanliness and drove up energy demand as Shove [8] has definitively demonstrated. The impact of women's domestic labour on the energy system has been recognised in history. In the UK, the strategic role of the housewife to energy policy was raised in the 1970s fuel crisis. The Hansard records the Secretary for State for Energy being asked to consider 'the housewife as 'the natural ally of the Minister's Department in conserving fuel?' and he replies that a large advertising campaign is underway to communicate the 
need for households to conserve [9]. Housekeeping entails decisions that impact national energy infrastructure. The relationship between domestic energy consumption and women is therefore an ambivalent on one. On the one hand the role of the housewife is imbued with agency and recognized as a source of power. But on the other hand this power stems from performing a type of labour that is under-valued and unevenly distributed through the household and through society [10].

Some feminist critiques argue for women's liberation from domestic labour, but anthropological accounts paint a more complex picture by centralising women's own experiences and giving voice to women rather than speaking for them. Such accounts argue for an appreciation of women's agency rather than a universalizing account of home as a site of subordination [11]. In these ethnographies chore-doing is shown to be a way of expressing love [12] and performing a cherished and hard won identity [13]. Chore-doing is about managing a household's consumption, its finances and its morality. Most recently, Morosanu's [14] ethnography of household energy use associates chore-doing with a form of 'ethical imagination'. Based on observing the way people care for their household members through anticipating their 'needs, habits, preferences, and dislikes', Morosanu suggests a mode of operating which she calls 'the Mother-multiple'. This mode can be occupied by anyone 'when engaged in kinship-situated caring' rather than specifically by a woman who has children. Morosanu explains that as well as providing an analytical tool to understand how and why things happen at home, it can also offer a tool to think about a more sustainable future. The ability to operate in a mother-multiple mode of being could be a way to tackle overconsumption, or work towards global justice perhaps (p.136).

These anthropological analyses of why chore-doers do chores and what it means to them share a material culture lens. Material culture focuses on social relationships and identities that people build through their interaction with their material surroundings, as exemplified by Pink's work on gender, sensory environments and laundry doing $[11,15,16]$ and Miller's approach to housing and materiality [17-20]. In the case of DSR, a material culture approach means questioning how people's use of their energy consuming appliances is part of how they construct their home life and their family relationships. It means looking into the ways that flexibility products are integrated into these routines and relationships as well 
as questioning the broader politics of system change. Rowlands' [21] discussion of hierarchical materiality argues for anthropological analysis to account for how the political economy unequally structures participation in the materiality of everyday life and in doing so negatively or positively affects people's ability to produce themselves. As DSR brings energy system priorities into people's homes, their appliances become the materials with which they act and interpret their role in the energy system. A material culture lens helps analyse the tensions and possibilities this produces.

\section{Women and Demand Side Response}

Some studies of demand shifting have drawn attention to the role of women in carrying out domestic chores, but there has not been extensive critical interrogation. For example, Torriti [22] writes 'women 'start' the evening peak' due to their child care obligations and choredoing, at a time when men are more likely to be at work or travelling home, and concludes with a hypothetical statement that '[a]sking this type of household to shift loads during the evening peak is unlikely to be followed up by action'. However a study of energy efficiency campaigns in Sweden found that women did respond to variable energy pricing by flexing their chore-doing, even though this added to their workload [23]. In Denmark, a DSR trial found that women flexed electricity consumption more than men, without increasing the time they spent on chores, leading the researchers to suggest that DSR policies and products should be targeted at women[24]. In the UK, a large-scale trial of time of use tariffs also identified that the most shiftable tasks were 'solitary' ones like laundry and dish washing, which are typically 'performed by a woman' [25]. The researchers stop short of proposing policy target women, but suggest that the complexity of the gendered division of labour be recognised [26]. There is a need to take better account of chore-doing and the gendered nature of energy consumption both to avoid negative unintended consequences for the gendered division of labour, but also to improve the design and implementation of smart electricity systems [6].

The absence of chore-doing in the design and delivery of smart electricity systems has been identified and comprehensively critiqued by Strengers [27]. Chore-doing should be handed over to feminized Al assistants such as Cortana, Siri, or Alexa who will orchestrate loT 
appliances on consumers' behalf to create comfort and capture value. Such imaginaries have been critiqued by Strengers [27] and Strengers and Nicholls [28] who argue that they stem from a future being built to serve 'Resource Man', a consumer archetype drawn by the male-oriented industries of engineering, economics and computer science which are building smart systems. 'Resource Man' micro-manages energy through smart home technologies, but is created with in a 'smart ontology' that ignores the realities of domestic labour. Strengers warns that 'Resource Man will form the boundaries of what an electricity consumer should be' [27]. Variably priced electricity is seen by the UK government as a way to improve the electricity market for consumers enabling them to gain benefits through their active participation while reducing the carbon intensity of supply $[29,30]$. However Strengers' warning asks us to consider those who do not engage with the electricity market in this way, and to reflect on the exclusions or penalties that may be experienced by those who find it difficult to chase the best tariffs [31]. Such concerns are valid to raise in the context of a DSR trial in social housing in the UK, a country where despite liberalising the sector in 1990s, the majority (68\%) of the population still avoid actively engaging as market participants and those that do tend to be on higher incomes [32]. It is worth using other frameworks to understand people's participation in the energy system, because as other trials have shown, response to DSR prompts are incorporated into household routines and rationales [26] which can produce confounding results as people act when market logic suggests they would not [33].

\section{Energywise: an experimental trial of DSR products}

Energywise was funded through the UK's energy regulator OFGEM and took place between 2014 -2018, in Tower Hamlets, a London borough which scores highly on the index of multiple deprivation. The project consortium was led by London's District Network Operator (DNO) UK Power Networks, and included one of the UK's largest energy companies (British Gas), two social housing providers (Poplar HARCA and Tower Hamlets Homes), and a community organisation the Bromley-by-Bow Centre which provided a bilingual field officer team to liaise with the local Bangladeshi population. UCL was the academic partner with responsibility for the trial design and some data analysis. My own role on the project was to lead the social research. I was brought into the team after the trial had been designed and 
had started recruiting participants. The trial was not designed to understand the relationships between gender and demand shifting, but the need to investigate it was evident. Tenancies in the social housing are predominantly held by women (Table 1) and therefore the majority of people who consented to take part in the trial were women (Table 2).

Table 1: Gender Composition of Named Tenants in Household (aggregated data provided on request by the housing providers in 2018)

\begin{tabular}{|l|c|}
\hline & Trial housing providers \\
\hline Female & $51.47 \%$ \\
\hline Male & $35.31 \%$ \\
\hline Other gender identity & $0.01 \%$ \\
\hline Joint & $13.21 \%$ \\
\hline
\end{tabular}

Table 2: Gender of Energywise consentees

\begin{tabular}{|l|r|r|r|}
\hline & $\begin{array}{c}\text { Approached } \\
(\mathbf{n = 1 3 5 2 )}\end{array}$ & $\begin{array}{c}\text { Consented } \\
(\mathbf{n = 5 3 8 )}\end{array}$ & \multicolumn{1}{c|}{$\begin{array}{c}\text { DSR active } \\
(\mathbf{n = 2 3 8})\end{array}$} \\
\hline Female & $57.2 \%$ & $57.6 \%$ & $61.0 \%$ \\
\hline Male & $39.7 \%$ & $39.4 \%$ & $38.6 \%$ \\
\hline Unknown & $2.4 \%$ & $2.8 \%$ & $0.0 \%$ \\
\hline Joint & $0.7 \%{ }^{1}$ & $0.2 \%$ & $0.4 \%$ \\
\hline
\end{tabular}

Furthermore, the recruitment process meant participants had certain factors shaping their engagement with a DSR product. First, they were recruited through their housing provider and they had to be customers of British Gas, the formerly state-owned energy company which remains the country's largest supplier (29\% of the UK market according to 2018 OFGEM data). It was clear through the recruitment phase that there was a reluctance to switch away from British Gas [34]. Once recruited if households did switch, they left the project. Therefore the participants did not fit the profile of 'active market switchers'. In addition, a proportion of participants used prepayment meters (PPM) for their electricity. Tariffs available on PPMs are typically more expensive than tariffs available on other

\footnotetext{
${ }^{1}$ The contact data supplied by the housing providers for the recruitment process typically listed only one name per household. The aggregated data supplied by the housing providers on the gender of tenancy holders indicated a larger proportion of joint household heads.
} 
meters. The participants therefore do not fall into the category of active energy market participants who are willing and able to get the best electricity tariffs available.

Second, the loads that were available to participants to shift were limited. The trial funding source limited energy shifting to electricity. Through a duty of care to the participants homes without gas central heating were excluded. This meant that the biggest electricity loads available to residents were their kitchen and laundry appliances. Whilst some homes had secondary electrical heating, the qualitative research suggested that its use was limited. Error! Reference source not found. shows that most people had washing machines, but only a few had electric ovens or tumble driers.

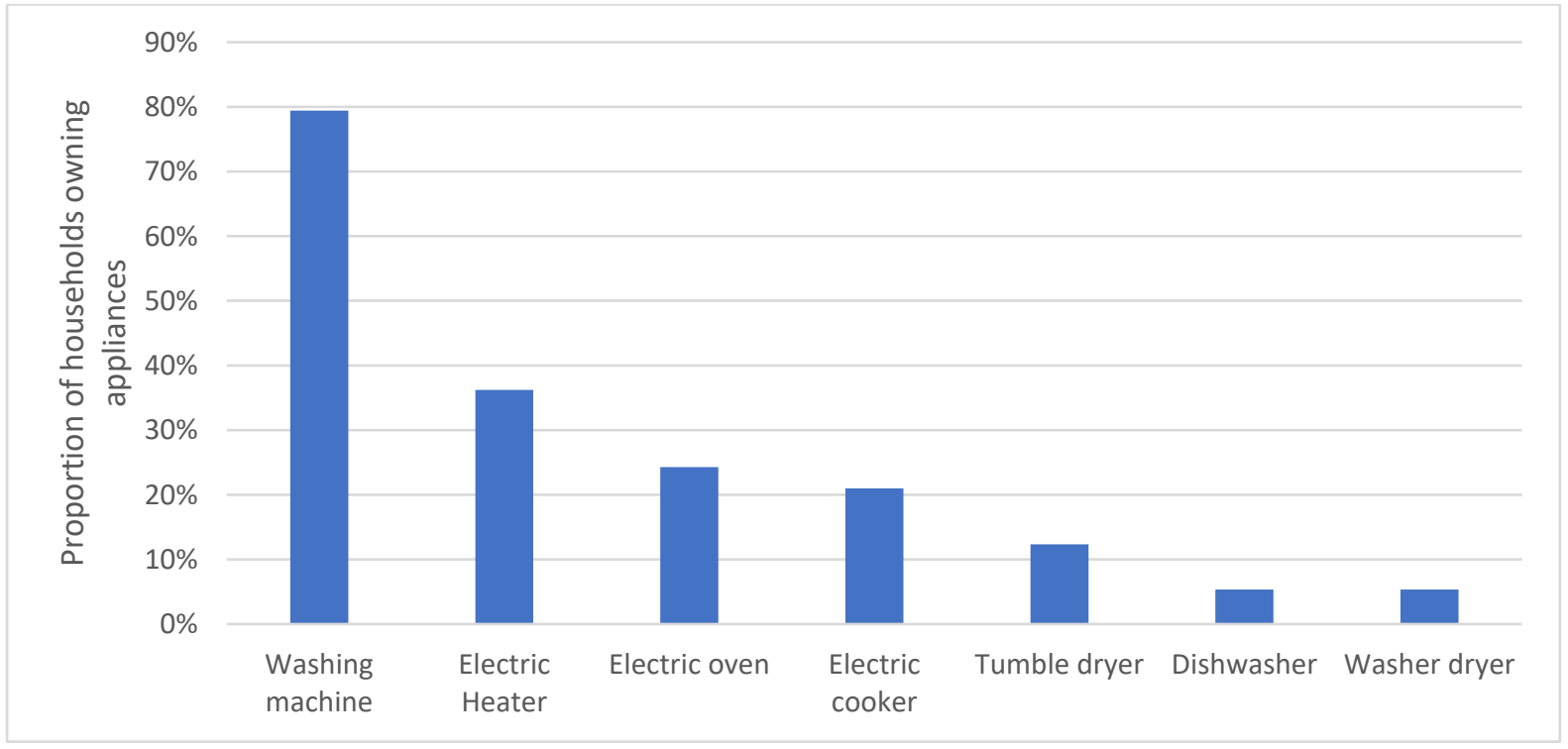

Figure 1 Appliance ownership for Energywise DSR consentees

The project was composed of two trials, this paper focuses on the 'energy shifting trial', an experimental trial of two DSR products, a Time of Use (TOU) tariff for customers with smart credit meters and a Critical Peak Rebate (CPR) programme for customers with smart prepayment meters. The two flexibility products were designed to be economically nonpunitive, meaning that the households would not be financially worse off by participating, even if they were unable to actively respond. The two products were:

1)HomeEnergy FreeTime, a Time of Use (TOU) tariff designed for households using smart credit meters, adapted from a commercial offer available from British Gas at the time the trial started. This offered free electricity between 9am-5pm on either a Saturday or Sunday. 
2) Bonus Time: a Critical peak rebate (CPR) programme designed for households using smart prepayment meters. This offered an incentive to households to reduce their electricity consumption during 'critical peak' events, which for Energywise were typically 6 hour periods $(5 \mathrm{pm}-11 \mathrm{pm})$ covering the weekday evening peak. Participants received an SMS message the day before a critical peak event and another 2 hours before its start. For every unit of energy saved in this period, they received 10 times the kilowatt hours as a financial credit loaded onto their prepayment meter.

The 296 households on trial 1 were rolled onto trial 2 and offered a flexibility product according to their meter type. The credit meter households were asked by their energy supplier to switch to a TOU tariff and 173 consented to switch. The prepayment households were asked by the project field officers to try the CPR offer and 82 consented to receiving shifting notifications to their mobile phones.

\section{Qualitative research}

To understand how households were making sense of these offers and reacting to them, the qualitative research team (myself, a sustainability consultant and the field officer team) ran focus groups and carried out semi-structured interviews with participants. The focus groups took place quarterly over the three year period, and were designed to trial project communications, test ideas and get feedback from participants about the project generally. All participants were invited to participate in the focus groups and were offered a $f 10$ voucher per meeting to incentivize attendance. During the energy shifting trial participants were divided according to meter type so they could discuss the specific flexibility offers they were on. We ran four focus groups for trial participants with prepayment meters and four for credit meter participants during the energy shifting trial. In total 24 people came to a focus group in this period, of which 23 were 'DSR active' households. Some of them came to only one, but some came to all. In addition, I carried out 21 semi-structured interviews with participants in their homes, three of whom had also been to a focus group. Therefore, I heard opinions about flexing electricity consumption from 42 of the 296 households on the DSR trial including three who had not opted in to either Bonus Time or HomeEnergy FreeTime ("not DSR active") (see Table 3). 
Table 3 Interviewees and Focus Group Participants by gender

\begin{tabular}{|c|c|c|c|c|c|c|c|c|}
\hline & \multicolumn{3}{|c|}{ Bonus Time (PPM) } & \multicolumn{3}{|c|}{ HomeEnergy FreeTime (Cr) } & \multicolumn{2}{|c|}{ Not DSR Active } \\
\hline & Women & Men & Couples & Women & Men & Couples & Women & Men \\
\hline Interviews & 7 & 3 & 1 & 4 & 3 & 2 & 1 & \\
\hline Focus group 1 & 3 & 2 & & 6 & 5 & & & 1 \\
\hline Focus group 2 & 3 & 2 & & 2 & 4 & & & \\
\hline Focus group 3 & 4 & 1 & & 3 & 5 & & & \\
\hline Focus group 4 & 2 & 2 & & 4 & 2 & & & 1 \\
\hline
\end{tabular}

I interviewed 11 women, five men, and four couples (man and woman) who had taken up one of the flexibility offers and one woman who had not ("not DSR active"). The composition of the interviewees' households included three single person households, one of whom was over 65, five women with school age children, five heterosexual couples with school age children, two heterosexual couples without children at home, four households with adult children and their parent(s) and two households with three generations (school age children, parents and grandparents). Seven of the households had Bengali as their first language, and I was supported by Rothna Begum, a bilingual field officer to recruit and carry out these interviews. Data on household size and income were collected through a survey at the start of the trial. The tables below show the range of incomes (Table 4) and household sizes (5) for all trial 2 focus group participants and interviewees.

Table 4 Weekly household income for focus group participants and interviewees (Survey data)

\begin{tabular}{|l|r|}
\hline \multicolumn{1}{|c|}{$\begin{array}{c}\text { Weekly household } \\
\text { income }\end{array}$} & $\begin{array}{c}\text { No. of } \\
\text { households }\end{array}$ \\
\hline$<£ 200$ & 13 \\
\hline$£ 200-£ 399$ & 9 \\
\hline$£ 400-£ 599$ & 4 \\
\hline$>£ 599$ & 9 \\
\hline Unanswered & 42 \\
\hline Total & 7 \\
\hline
\end{tabular}


Table 5 Household size of focus group participants and interviewees (survey and interview data)

\begin{tabular}{|l|c|}
\hline Household size & $\begin{array}{c}\text { No. of } \\
\text { households }\end{array}$ \\
\hline 1 person & 8 \\
\hline 2 people & 12 \\
\hline 3 people & 7 \\
\hline 4 people & 7 \\
\hline 5 people & 2 \\
\hline 6 people & 3 \\
\hline 7 people & 3 \\
\hline Total & 42 \\
\hline
\end{tabular}

All participants were invited to be interviewed through a newsletter advert, but in the absence of people requesting to be interviewed, we approached participants. The first round of interviews took place in the first three months of the trial to check comprehension of the offers and focused on households with Bengali as their first language. The second round of interviews took place in the last three months of the trial and we selected interviewees to get a range household sizes, ethnic diversity, electricity consumption profiles and household income. The same semi-structured protocol was used in both rounds. Discussion topics were households' homes and appliances, daily routines, experiences of the smart meter and IHD installation and use, reasons for consenting to the trial and to the 'flexibility offer' in particular and steps taken to shift electricity consumption. The interview transcripts were coded in Nvivo using a combination of inductive and deductive approaches. During a first pass the interview material was coded to allow the trial partners to understand whether people were shifting and included codes such as 'actively shifting', 'aware, but unable to shift', 'not trying to shift'[35]. During a second pass I coded the interview and focus group material deductively to understand how and why people were responding. The most often stated motivation to shift was the possibility to save money or earn credits, however the ways that people were shifting and the reasons that people were not shifting, gave rise to other questions around how shifting related to social reproduction and appliance use. 
The gender insights discussed in this paper therefore stem from qualitative data produced within the logic of an experimental trial which selected households, created interventions and tested responses. But I have adopted a feminist lens to critically explore the evidence this produced on ways gender was implicated in making the trial work. By combining perspectives in this way, I am able to present the evidence created in the trial about who responded and how, but am I also aim to reflect critically on this evidence and its absences.

\section{Responders}

The potential to save or earn money was stated by most focus group members and interviewees as their main motivation to participate. However participants were aware their response to the DSR offers would be limited by the realities of family life. People mentioned the arrival or departure of family members, going back to work, babies starting at nursery, appliances breaking down, sick mothers in law to be visited, a litany of domestic obligations and realities that got in the way of how they could act on their consumption. The focus groups became an opportunity for members to swap tips and exchange tales of strategy and resultant successes or failures. One woman's ability to mobilize the extended family living under her roof was held in esteem. She described her tactics from sticking up notes on bedroom doors notifying of the chore schedule to cooking her Sunday roast on a Saturday with her electric oven. This exemplary management was countered with examples of creative resistance; another woman described finding her teenager hiding under the bedcovers with an extension cord providing an illicit connection to the household's electricity supply "She hides a cable behind her bed, plugs in her phone, iPad and everything and pulls the duvet over her so I don't know what she's doing." (Focus group notes: 7th July 2017).

Other studies have found that family members can get in the way of flexing energy demand, in particular where the husband or father of the household consents, but their wives and children undermine their efforts or come into conflict with the strategies they use [36]. However the qualitative research from Energywise showed ways that participants tried to manage energy shifting offers in respect to family life. Two households on the HomeEnergy FreeTime tariff explained how their decision about their free electricity day had been taken 
in respect to household chores. One couple had discussed the offer together, identifying Saturday as the main chore day and therefore the most appropriate to have their 'FreeTime'. The other couple had had to change their initial choice. Mina explained her husband 'chose Sunday, then I said no because on Saturdays I use the machine quite a bit obviously the school uniforms [need to be washed]'

Nadia was a single working parent who had opted into 'Bonus Time', the critical peak rebate scheme. She had three children and had developed her shifting strategy around them. Laundry was one of the easiest things for her to shift as other trials have evidenced $[24,25]$, however this was not because it was a 'solitary task' down to her alone, but because her eldest daughter was able to help out. Nadia explained that she sometimes asked her teenager to put a wash on while she was at work so it would be finished before the critical peak event. Nadia had found the in-home display useful in identifying which of her appliances used a lot of electricity which had led her on one occasion to target her electric oven. Nadia described rushing to finish cooking the family dinner before one critical peak event which unusually had taken place at a weekend. The call to shift her demand had also made her question it. She commented: "It makes you think of how you do things in your house, to reduce it really. And do not be so obsessed with doing a wash. It can wait, a wash can wait." Not only was Nadia aware of how her own routines and priorities related to electricity demand, but she had also come to question them.

Reducing waste and being disciplined were frequently repeated as motivations by active shifters. Constance was a regular focus group attendee who found the wastefulness of her family frustrating. She described using Bonus Time to support her struggle to keep the family's consumption and expenses in check. In the meeting held six months into the DSR trial I noted: "[Constance] is often at work. Forwards text to household members if at home - including children. Uses Bonus Time to encourage less TV and more homework" (focus group notes: 5th October 2017). Constance's husband was a habitual tea drinker, and Constance had taken to filling a thermos of hot water before the start of a 'Bonus Time'. This meant he could drink hot drinks during critical peak events without using the kettle. This was a strategy that other focus group members were so impressed by that they asked for it to be shared via the project newsletter to all other Bonus Time participants. 
The shifting calls from Energywise prompted people to experiment with their appliances in their efforts to get value from the offers. Some households found the in-home display helpful in working out the energy intensity of different appliances and then adjusted their consumption in line with the knowledge. Maria for example, checked which of her two electric heaters used less electricity and then encouraged her daughter to use the lower consuming one. Others looked at how to displace their consumption away from or on to electricity depending which offer they were on. Amir for example found his microwave oven could also bake, enabling his mother to cook using free electricity rather than use their gas oven (Focus group notes 26 April 2017). Pat described using her electric heater to tackle damp in a bedroom, rather than her gas central heating (Focus group notes 26 April 2017). When participants swapped tips about tea-making or microwave baking, there was a sense of enjoying the attempt to discipline their electricity consumption. As one focus group participant commented "It makes you feel good to know you can actually discipline yourself' (focus group notes: 5 th October 2017. The fun of the challenge has been identified as a motivating factor in other energy shifting trials. Ozaki [29] suggests this element of fun opens up the possibility to 'recraft practices' and make the novelty of shifting turn into a more sustained ability to consume electricity flexibly. However gamifying domestic DSR is troubling for Goulden et al.[30] who see it as a top down mechanism for aligning consumer behavior with energy system priorities, without allowing people to engage more deeply or critically with the energy system or their consumption. Powells and Fell [37]draw attention to the distributional implications of different ways of gaining flexibility. For Energywise participants these efforts at creative shifting need to be contextualized within the realities of making ends meet for low income households. While they expressed enjoyment at experimenting with appliances, it was also a way of differentiating between necessary and unnecessary consumption in order to cut down household outgoings.

Most interviewees and focus group participants stated that the main attraction of the offer was the potential to save money. However the link between strategies deployed and credits earnt or costs avoided was diffuse. This was due in part to the lag between the households' weekly shifting activities and the statements of earnings they received quarterly. It was also because participants were well aware that other domestic realities had 
more impact on their electricity bill than their shifting ability; mentioning visiting family members or broken down appliances for example. Credits were discussed in terms of rewards for participation rather than attributed to specific electricity management. Amy, who came to a focus group after receiving her first quarterly statement discussed the positive response she had got from her family when she showed them the $£ 13.00$ credit she had earnt for the first three months; "everyone was clapping and praising me" she said (focus group notes: 5th October 2017). In some respects, the non-punitive offer was able to validate and value the skill of typically unvalued domestic labour, beyond the financial value it gave. It brought these women's efforts recognition from an energy company in the form of a credit, which was then translated back into love and affection by her family in recognition of her ability to manage the home.

This disconnect between the value of chore-doing and the value of electricity is further illustrated by Nadia. As mentioned above, she was putting considerable effort into shifting, targeting her family's meal times and questioning her own laundry habits, but she did not adopt the same the effort when it came to seeking out the cheapest energy tariffs available on the market. I asked her about her use of a prepayment meter to pay for her electricity rather than a credit meter, which could enable her to access cheaper tariffs. The effort to change the meter was not something she had done because she did not want to be bothered with phoning the energy company and "sorting all that out". It seems Nadia found using her appliances an easier way to explore value creation in the electricity system than the options available through her meter. She used her appliances to try alternative modes of consumption from delegating chore-doing to reconsidering the chore itself.

Other households found it hard to find any areas of consumption to reduce. Instead, the DSR products provoked a reflection on the inherent value of the electricity system. For example Bob lived alone on a small income and managed his electricity costs very closely. He opted into the DSR trial even though he did not think that he would be able to generate much credit through the incentive scheme. He nonetheless wanted to participate because he felt it was a good thing to be doing. In the final focus group when participants were reflecting on the project, Bob referred back to an earlier point in the trial when we had explained why DSR produced value for the electricity system. He explained that his 
motivation to join in was the general sense that it was good, and that we should be trying to reduce the generating plant needed to cover peak capacity. His perspective was echoed by Julie, also a retiree who lived on her own. She was the only member of the focus groups who was clear that her primary motivation was environmental. Julie felt that living on her own she had little to cut back on, but opting in had given her a way to participate in change.

\section{Non Responders}

May demonstrates an opposite experience. May is not an English speaker and relies on her children to translate official things. She said no to the ToU offer. I went, with Rothna, to understand her reasons for saying no. We started talking about energy in general. She explained that the costs were a constant concern and that she had sought help to reduce them. When discussing her household routine she explained that she did laundry at the weekend, describing her most recent weekend, she had put two loads on a Saturday. May is currently on her supplier's standard variable tariff, typically the most expensive, and although energy costs were a concern to her, she had not understood tariff options and decided the ToU tariff was probably not worth it. The trial's recruitment campaign had failed to explain that if she had been able to run one load of washing in the 9-5 period of HomeEnergy FreeTime (HEFT) she would have made a saving. It is true that the saving would have been small, and arguably not worth any effort. But it is also possible that by talking in terms of tariffs rather than in terms of household chores and schedules the project had failed to sign up someone who was struggling to meet their bills and who could have financially benefited from switching to a simple static non-punitive time of use tariff with no change to her current household routine.

In terms of the men I spoke to there were two typical responses; those that felt they had been able to shift some consumption, or benefit from the FreeTime; and those that had signed up because there was nothing to lose, but had not tried to shift household electricity consumption. The shifters were either men living alone or men who had explained the project to female household members and these wives, mothers and daughters-in-law carried out the chores in line with the offers. However more common was to hear from the non-shifters; men who had consented to the DSR offer but who were not in charge of the 
chores and who had not told the female chore-doer in their house that they were on a DSR initiative which provided an economic reward if electricity consumption was flexed according to specific times.

This was the case in Mo's home. Mo lived with his wife and two young children. They had a smart prepayment meter and he had consented to the Bonus Time offer. Mo had the account with the energy supplier and was in charge of the bills. "[A]ll the bills are my headache" he explained. However his wife was in charge of the cooking and laundry. Mo's house had an electric oven and a tumble dryer, and therefore had some energy intense appliances that could be used to earn credits. I asked if he forwarded the SMSs to his wife, or told her when there was a critical peak event, but he had not told her they were on Bonus Time. Asking her to take on the responsibility of doing chores to earn money would be too much; he did not want to add the burden of responding to a CPR event. Nonetheless Mo was happy with the project, he explained that to him the broader value was becoming more energy aware, and remembering to switch off lights. Mo explained that for him, it's just the general saving, that's what I'm happy with. For the credit, I'm not worried at all'. This sentiment was echoed by $\mathrm{Al}$, a pensioner living with his wife and adult son. "We just plod on as we normally do. She cooks her meals at the usual time. If it happens to go into Bonus Time, we're not going to turn the cooker off to save ... we just carry on."

These non-responders present a dilemma for the trial because they demonstrate the need to communicate in terms of chore-doing, in May's case so she could access cheaper electricity via a tariff switch that was compatible with her current household routine, or in the men's case to perhaps revise understandings of the effects achievable with a nonpunitive DSR offer. For Mo and Al, saving energy was about not wasting energy by turning off lights when not at home. Both mentioned lights on in an empty room as being something they could not understand and would take other family members to task over. Our project had not conveyed the sense that other appliances had a bigger impact on household spending on electricity, nor that changing the way appliances were used and chores ran could generate individual savings and system wide efficiencies. But May's question of whether it is worth it is a valid one, as is Mo's questioning of the added requirement for chore-doing to generate system level gains. 
A difference between male and female consentee responses was also apparent in the Danish trial [24]. Men who received the shifting text messages produced less of an effect then women who received text messages because they were not responsible for the chores that could produce a response. Similarly in Energywise, where there was a split between consentee and chore-doer this fell along gendered lines and affected the household's response. I did have conversations with male consentees who were chore-doers and who were trying to align their own and other household members' chore-doing with the DSR incentives, but more common were the male consentees who were not the primary choredoers and had not communicated the offer. I did not have a conversation with a female consentee who was not also the main chore-doer.

\section{Discussion: Introducing Flexibility Woman}

What these conversations suggest to me is that Flexibility Woman exists. In contrast to 'Resource Man' who emerges from future-oriented work as the ideal consumer soon to be realised, Flexibility Woman was visible empirically in the DSR trial. She had knowledge about her family's consumption habits, the loads in home and the schedules of life that shaped her household's electricity demand profile. She may not have talked in these terms or made such connections explicitly, but she had this knowledge because she knew when the laundry had to be done and when it could wait, she knew when meals were to be eaten and therefore when food needed to be cooked. When asked to shift electricity consumption in order to contribute to system level benefits and generate individual rewards, she tried. She differentiated between necessary and indulgent consumption, she arbitraged between gas and electricity, and she developed strategies to recruit other household members into her response, delegating the responsibility to act in her absence, or putting in place simple technical fixes like using a thermos flask to store energy and shift its consumption. She managed her household's energy consumption in line with her management of the household's money and its morality using it to reproduce family values of thrift and discipline or demonstrate family care. 
Strengers [27] warns against creating new 'consumer archetypes' specifically referring to 'domestic woman' as an obvious counter to Resource Man which should be avoided. However, I create 'Flexibility Woman' not as a consumer archetype, but as a construct stemming from my own experience of interpreting these households' shifting strategies from within the logic of an experimental trial as well as through a feminist lens that struggles to accept the trial's assumed gender neutrality. The first perspective applauds the mobilisation of household members and appliances in creative chore management as an 'ideal responder'. The second perspective puts this ability to flex into a longer history of survival strategies developed by a less dominant social group. I create Flexibility Woman as a lens with which to understand the role of chore-doing in producing demand flexibility and the opportunities and inequalities this involves. This lens draws attention to two discussion points; first the relationship between social reproduction, value production and demand shifting, and second the materiality of chore-doing and the role of appliances in allowing participants to experiment with energy system transition.

\subsection{Amy's Applause}

To consider the relationship between social reproduction and demand shifting I want to return to the applause Amy received for generating a credit for demand shifting. Feminist perspectives point to the necessary role that unwaged labour plays in contemporary capitalism and the over-looked value that women in particular produce through their role in social reproduction [10]. When Amy is applauded for generating income through her choredoing and management of the home it raises the question about how and for whom she is creating value. Electricity consumption is wrapped up in caring for the family $[14,38]$. Does the credit earnt indicate recognition of the value that caring for domestic others creates, that it is in itself a social good? Given the neoliberal context within which the UK's electricity market is regulated, does this credit mark the commodification of labour and a process through which Amy will be alienated from the value that she produces?

In a related point, how should the actions of men who did not communicate that they had accepted a DSR offer to their female chore doers be interpreted? Or the experts who feel demand shifting is too much of a burden on family life? On the one hand this is explicitly about their recognition of and concern for reducing the burden of domestic labour on 
women. On the other, a feminist perspective requires that we consider whether such concern works to dismantle the primacy of the public sphere as the space of value production and the continued relegation of the domestic sphere and the social reproduction it contains as unimportant. A critical lens could interpret this sheltering as reinforcing the assumption that systemic change is not produced by considering when and how the laundry gets done. Trivialising the role of chore doing in analyses of smart systems is problematic. The qualitative insights from this trial suggest it will affect the outcomes of policies designed in blindness to gender impacts. In addition, the participants' experiences add a glimpse of a feminist form of politics that can be found in household demand shifting. This is hinted at when consumption is managed with rather than despite the family and is used to reproduce social values. It is hinted at when the chore-doer reflects critically on the need for the chore itself. It is hinted at when the decision to opt in is based not only on an assessment of individual rewards, but also by a motivation to participate in systemic change.

\subsection{Constance's Thermos Flask}

The second area I want to draw attention to is the appliances people used and the way they used them. In particular, I want to reflect on the thermos flask Constance used to shift her husband's kettle boiling outside a critical peak event. Following the material turn in social sciences, I locate political potential in the realm of objects. Marres' [39] discussion of 'environmental teapots' is relevant here. She argues for an understanding of object-politics that stems from an object's ability to be 'loaded with politics'. She defines this in contrast to Akrich's [40] idea of scripted objects which create specific forms of politics through the subject positions they implicitly create for their users. For Marres [38], the point is not to focus on how the subject is produced, but to analyse 'the explicit investment of objects themselves with political and moral capacities'. She argues that technology can assist object-politics, using the example of an Arduino-assisted teapot that can visualise to users the current mix of the electricity supply at the point it is boiled. Marres suggests analysing the source of the norms that are loaded onto objects, but her methods of analysis focus on the public sphere, rather than the domestic as a source of norms. From this perspective, a flexibility product such as a time of use tariff or critical peak rebate is a technology designed to make the materiality of the home resonate with normative potential, from neoliberalism to techno-optimism. My interest is in the way that Constance experiments with her 'loaded' 
materiality in a way that aligns with domestic values in contrast to dominant commercial or policy interests.

Constance identified the service the electricity was being used to provide (a hot drink), reflected on how to get this service without using peak time electricity and came up with a simple, low tech option. Her use of a thermos articulates the value she placed on both thrift and discipline in her family. It is antithetical to one of the corporate drivers for domestic DSR which is the opportunity to sell new technologies and services. Goulden et al. [30] make this point in their analysis of the UK's developing DSR market. They argue that the blurring of smart home technology markets with energy markets is creating an opportunity for domestic DSR through automation and gamification. It allows for energy to be optimised inside homes of passive and disengaged consumers, however Goulden et al. [30] caution that recognising DSR only as a market for tech optimisation curtails deeper critical engagement by consumers about demand. It also introduces the paradox that participation requires increased electricity consumption [27] and raises the question about who is excluded.

Rowlands [21] takes a dialectical view of material politics, focusing not only on the agency of materiality, but also how this is productive of human agency. He asks us to consider the question of hierarchical materiality and look at how the political economy can unequally structure participation in the material world and limit people's abilities to produce their worlds. Dominant corporate interests may focus on new forms of electricity consumption, but applying Rowlands' perspective, excluding those with low levels of electricity consumption and few appliances limits them from thinking of themselves of constituents of the smart electricity future. Domestic labour becomes marginalised in the face of new ways of consuming electricity, rather than recognised as a primary concern and a way of facilitating engagement with and understanding of low carbon transition. A smart electricity grid and associated variable pricing may enable some energy consumers to capture value with their female voiced, app-based domestic manager conducting an orchestra of IoT appliances. People on lower incomes who cannot equip themselves with these substitute wives may find they have to shift or are at risk of being too poor to access the cheapest electricity. Flexibility Woman is therefore a warning that chore-doers cannot become a low 
cost option for the energy system who produces system value through their under-valued domestic labour. But nor should her home or her agency be rendered immaterial to the low carbon energy transition. To do this would risk designing a future based on the continuation of existing gender and class inequalities.

\subsection{A word of caution}

I want to end the discussion with a comment on the limitations of the empirical data and my analysis. What I recognised in these participants' accounts, and what I have tried to reflect on in this analysis, was the possibility for Flexibility Woman to be more than consumer archetype, and a source of political possibilities. However the trial was not designed to explore the interaction between DSR and gender and the qualitative data it produced was limited. My analysis is therefore a call for more detailed critical research into what happens when households are invited to participate in demand shifting. DSR is opening up established categories of producer and consumer, it is loading energy politics onto the materiality of the home. There is therefore an opportunity to rethink the social relations created through energy infrastructure including gender relations and to carry out this critical reappraisal with those who opt in. While the evidence produced in Energywise has not allowed for this form of interrogation in detail, it has identified the types of questions that are not being asked and the need for research that can investigate them. Flexibility Woman is an opportunity to question how gender and intersectionality can be included in building smart electricity systems. She is a prompt to question how a gender sensitive DSR offer might be designed and what a feminist energy future might look like.

\section{Conclusion}

The Energywise trial has provided more evidence that when flexibility products such as Time of Use tariffs and Critical Peak Rebate schemes target appliances, women's chore-doing is central to carrying out DSR. Households' experiences have been discussed in terms of willingness to shift and strategies deployed and have shown how electricity consumption embedded in domestic life can nonetheless be flexed through creative management, typically carried out by women. I have centralised participants' accounts in order to render them not as isolated chore-doers in charge of shiftable loads, but as active agents 
responsible for the reproduction of family life and family values who are capable of critically reflecting on their household's energy consumption and of acting on this reflection. The discussion has raised two practical implications. First, flexibility product developers should consider communicating these types of DSR offers to households in terms of assessing chore-doing routines and responsibilities in order to identify appropriate tariffs or flexibility products and the appropriate consentee in the household. Second, policy-makers concerned with distributional impacts should be mindful that if access to cheaper electricity depends on co-ordinating chores with DSR schedules lower income households and women in particular may find themselves disadvantaged. Rather than suggesting that appliancebased DSR should be avoided in order to avoid burdening women, instead I draw attention to questions about who participates in emerging electricity markets and under what conditions. Contributing to the evidence from other trials that people act during critical peak events in ways that confound expectations, this trial has demonstrated a willingness to produce electricity system flexibility by acting on household consumption through choredoing. The introduction of smart meters and flexibility products to the electricity market constitutes a shift in the way energy is supplied and used. As such electricity using appliances become the material through which people experiment with the smart energy system and adapt it to their own habits and modes of caring and future building. Choredoing is central to this experimentation. In this paper I have argued for recognition of people's experimentation and their attempts to shift consumption as a form of agency and contribution to energy system transition that is not conditional on the size of the loads in their home.

\section{Funding}

Energywise was funded through the second tier Low Carbon Networks Fund, 2014-2018

\section{Declaration of interests}

The author declares that they have no known competing financial interests or personal relationships that could have appeared to influence the work reported in this paper.

\section{Acknowledgements}


The author would like to thank all the Energywise team and participants, in particular those that gave their time to come to focus groups or be interviewed about their experiences. Thanks also to Emma Jones at CAG Consultants and the Bromley-by-Bow Centre field officer team who supported the qualitative research, in particular Rothna Begum who accompanied me and translated from Bengali. Thanks also to David Shipworth, Jenny Crawley, Simon Elam, Mike Fell and the PACE research group whose discussions on the project shaped my thinking. 


\section{References}

[1] M.J. Fell, Taking charge: perceived control and acceptability of domestic demand-side response, (2016) 1-283.

[2] J. Torriti, R. Hanna, B. Anderson, G. Yeboah, a. Druckman, Peak residential electricity demand and social practices: Deriving flexibility and greenhouse gas intensities from time use and locational data, Indoor Built Environ. 0 (2015) 1-22. doi:10.1177/1420326X15600776.

[3] HM Government, Upgrading Our Energy System: Smart systems and flexibility plan. London, UK., London, 2017.

[4] S.E. Ryan, Rethinking gender and identity in energy studies, Energy Res. Soc. Sci. 1 (2014) 96-105. doi:10.1016/j.erss.2014.02.008.

[5] K. Standal, T. Winther, K. Danielsen, Energy Politics and Gender, in: K. Hancock, J. Allison (Eds.), Oxford Handb. Energy Polit., Oxford University Press, 2018: pp. 1-21. doi:10.1093/oxfordhb/9780190861360.013.6.

[6] K. Gram-Hanssen, M. Mechlenborg, L. Valdroff Madsen, A. Rhiger, Gender and ethical consumption of energy in smart homes, J. Consum. Ethics. 1 (2017) 111-119.

[7] R. Schwartz Cowan, More work for mother: The ironies of Household Technology from the Open Hearth to the Microwave, Basic Books, 1983.

[8] E. Shove, Comfort, Cleanliness and Convenience: The social organisation of normality, Berg, Oxford \& New York, 2003.

[9] HC Deb (17 March 1975), 888 (n.d.).

[10] H.L. Moore, Feminism and Anthropology, Polity Press, Cambridge, 1988.

[11] S. Pink, The sensory home as a site of consumption: Everyday Laundry Practices and the production of gender, in: E. Casy, L. Martens (Eds.), Gend. Consum., Ashgate Publishing, 2007.

[12] D. Miller, A Theory of Shopping, Polity Press, Cambridge, 1998.

[13] S. Pink, Home Truths : Gender, Domestic Objects and Everyday Life, Bloomsbury Academic, London, 2004. doi:10.5040/9781474214896.

[14] R. Moroşanu, An Ethnography of Household Energy Demand in the UK, Palgrave Macmillan US, New York, 2016. doi:10.1057/978-1-137-59341-2.

[15] S. Pink, K.L. Mackley, R. Moro, Hanging out at home : Laundry as a thread and texture of everyday life, 18 (2015) 209-224. doi:10.1177/1367877913508461.

[16] S. Pink, Home Truths: Gender, Domesticity and Everyday Life, Berg, Oxford \& New York, 2006.

[17] D. Miller, ed., Materiality, Duke University Press, Durham, 2005.

[18] D. Miller, The comfort of things, Polity Press, Cambridge, 2008.

[19] D. Miller, Behind closed doors, in: D. Miller (Ed.), Home Possess., Berg, Oxford \& New York, 2001: pp. 1-19.

[20] D. Miller, Appropriating the State on the Council Estate, Man (New Ser. 23 (1988) 353-372.

[21] M. Rowlands, Rowlands, M. (2005) 'A materialist approach to materiality",' in: D. Miller (Ed.), Materiality, Duke University Press, Durham, 2005: pp. 72-86.

[22] J. Toriti, Peak Energy Demand \& Demand Side Response, Routledge Taylor Francis, Abingdon, Oxon.; New York, NY, 2015.

[23] A. Carlsson-Kanyama, A.L. Lindén, Energy efficiency in residences-Challenges for women and men in the North, Energy Policy. 35 (2007) 2163-2172. 
doi:10.1016/j.enpol.2006.06.018.

[24] L. Tjørring, C.L. Jensen, L.G. Hansen, L.M. Andersen, Increasing the flexibility of electricity consumption in private households: Does gender matter?, Energy Policy. 118 (2018) 9-18. doi:10.1016/j.enpol.2018.03.006.

[25] G. Powells, H. Bulkeley, S. Bell, E. Judson, Peak electricity demand and the flexibility of everyday life, Geoforum. 55 (2014) 43-52. doi:10.1016/j.geoforum.2014.04.014.

[26] S. Bell, E. Judson, H. Bulkeley, G. Powells, K.A. Capova, D. Lynch, Sociality and electricity in the United Kingdom: The influence of household dynamics on everyday consumption, Energy Res. Soc. Sci. 9 (2015) 98-106. doi:10.1016/j.erss.2015.08.027.

[27] Y. Strengers, Smart Energy Technologies in Everyday Life, Palgrave Macmillan UK, London, 2013. doi:9780203108543.

[28] Y. Strengers, L. Nicholls, Aesthetic pleasures and gendered tech-work in the 21stcentury smart home, Media Int. Aust. (2017) 1329878X1773766. doi:10.1177/1329878X17737661.

[29] R. Ozaki, Follow the price signal: People's willingness to shift household practices in a dynamic time-of-use tariff trial in the United Kingdom, Energy Res. Soc. Sci. 46 (2018) 10-18. doi:10.1016/j.erss.2018.06.008.

[30] M. Goulden, A. Spence, J. Wardman, C. Leygue, Differentiating 'the user" in DSR: Developing demand side response in advanced economies,' Energy Policy. 122 (2018) 176-185. doi:10.1016/j.enpol.2018.07.013.

[31] S. Abram, B.R. Winthereik, T. Yarrow, Current thinking - an introduction, in: S. Abram, B.R. Winhereik, T. Yarrow (Eds.), Electrifying Anthropol., Bloomsbury Academic, London, 2019: pp. 3-24. doi:10.5040/9781350102675.0006.

[32] B. Williams, G. Waring, Consumer engagement in the energy market 2018: Report on a suvey of energy consumers, (2018).

[33] Y. Strengers, Air-conditioning Australian households: The impact of dynamic peak pricing, Energy Policy. 38 (2010) 7312-7322. doi:10.1016/j.enpol.2010.08.006.

[34] UK Power Networks, Vulnerable Customers \& Energy Efficiency: SDRC9.4 Customer Engagment, London, 2017.

[35] UK Power Networks, energywise: SDRC 9.5 The energy shifting trial report, London, 2018.

[36] L. Løgstrop, M. Nelson-Burk, W.S. Moshleh, W. Gunn, Designing anthropological reflection within an energy company, Ethnogr. Prax. Ind. Conf. Proc. 2013 (2013) 116-128. doi:10.1111/j.1559-8918.2013.00011.x.

[37] G. Powells, M.J. Fell, Flexibility capital and flexibility justice in smart energy systems, Energy Res. Soc. Sci. 54 (2019) 56-59. doi:10.1016/j.erss.2019.03.015.

[38] K. Burningham, S. Venn, Understanding and Practising Sustainable Consumption in Early Motherhood, J. Consum. Ethics. 1 (2016).

[39] N. Marres, The Environmental Teapot and Other Loaded Household Objects: Reconnecting the Politics of Technology, Issues and Things., in: P. Harvey, E.C. Casella, G. Evans, H. Knox, C. McLean, E.B. Silva, N. Thoburn, K. Woodward (Eds.), Objects Mater. A Routledge Companion, Routledge Taylor Francis, London \& New York, 2012: pp. 260-271.

[40] M. Akrich, The de-scription of technical objects, in: W.E. Bijker, J. Law (Eds.), Shap. Technol. Build. Soc. Stud. Sociotechnical Chang., MIT Press, Cambridge, MA, 1992: pp. 205-224. 